Research Article

\title{
Characterization of Short-Term Strength Properties of Fiber/Cement-Modified Slurry
}

\author{
Ping Jiang $\left(\mathbb{D},{ }^{1}\right.$ Tianhao Mao, ${ }^{1}$ Na Li $\mathbb{D},{ }^{1}$ Liang Jia $\left(\mathbb{D},{ }^{2}\right.$ Fang Zhang, ${ }^{1}$ and Wei Wang $\mathbb{D}^{1}$ \\ ${ }^{1}$ School of Civil Engineering, Shaoxing University, Shaoxing, Zhejiang 312000, China \\ ${ }^{2}$ College of Civil Engineering, Lanzhou University of Technology, Lanzhou 730050, China \\ Correspondence should be addressed to Wei Wang; wangwells@qq.com
}

Received 28 April 2019; Revised 8 August 2019; Accepted 30 August 2019; Published 14 October 2019

Academic Editor: Rosario Montuori

Copyright (c) 2019 Ping Jiang et al. This is an open access article distributed under the Creative Commons Attribution License, which permits unrestricted use, distribution, and reproduction in any medium, provided the original work is properly cited.

The recycling of construction waste slurry is an urgent issue that needs to be solved in urban construction. To satisfy the requirements of subgrade filling, mechanical properties of fiber/cement-modified slurry were investigated. Unconfined compression tests were conducted for 7 -day-cured specimens with a cement content of $5 \%, 10 \%, 15 \%, 20 \%, 25 \%$, and $30 \%$, respectively. Moreover, the effects of fiber contents $(0.25 \%, 0.5 \%, 0.75 \%$, and $1 \%$, respectively) were also investigated for the specimens with a cement content of $20 \%$. A formula satisfying the accuracy requirement was obtained by fitting the stress-strain curves using the back propagation (BP) neural network algorithm. Five parameters, including peak strength, failure strain, initial elastic modulus, residual strength, and energy dissipation, were used to characterize the short-term strength properties of fiber/cement-modified slurry. The analysis revealed that the cement content had a dominant effect on the short-term strength properties of fiber/cementmodified slurry, while the influence of fiber content was insignificant.

\section{Introduction}

The rapid development of urban construction has led to an abundant wastage of slurry produced during construction processes. Unreasonable discharge of waste slurry can severely damage the ecological environment. This has led to an urgent need to explore innocent treatment and resource utilization of waste slurry in future urban construction. Recently, the slurry has been applied as wall material [1], artificially synthesized aggregate [2], raw materials of cement [3], concrete admixture [4], raw material of glass [5], and road material [6]. Taking material composition of the slurry into account, it can be modified using certain treatment technology to satisfy the requirement of subgrade filling, which can provide a strategy for realizing resource utilization of construction waste slurry, saving land resources, and leading to a green and resilient modern urban construction [7].

The technology of enhancing mechanical properties of soft soil through cement has been widely applied in engineering [8]. It can be used in the dam, structure foundation, slope stabilization, vibration attenuation in high-speed railway, alleviation of liquefaction, stabilization (or solidification) of deep-mixed soil walls and contaminated soil, and so on.

Various studies have been conducted to investigate the influences of fiber on the property of cemented soil through unconfined compression test or splitting strength testing [9-11]. Several scholars also performed triaxial test [12], direct shear test [13], bending test [14], isotropic compression test [15], and cyclic shear test [16] on fiber-admixed cemented soil. The studies showed that adding fiber into cemented sandy soil or clay with constant low cement content (less than 10\%) could enhance its compressive strength, residual strength, and ductility.

As the slurry has similar engineering features as the soft soil with high water content, modification methods for soft soil could also be applied to solidifying slurry. It is known that a large quantity of cement is needed to stabilize the soft soil with high water content [14]. Sukontasukkul added fiber into modified soft soil with a cement content of $10 \%-20 \%$ and found that its residual strength significantly increased 
[14]. However, Consoli showed that the polypropylene fiber had a minimal effect on the mechanical performance of cemented soil with high cement content [17]. Festugato proposed a prediction model for unconfined compressive strength of cemented soil with low water content and took the fiber length into consideration [18]. Considering that construction waste slurry has high water content, large cement content is necessary for achieving expected strength [19-21]. Consoli considered unconfined compressive strength $\left(q_{u}\right)$ as a function of the porosity/cement index of compacted gold tailings-cement mixes [22]. Javdanian and Lee employed particle swarm optimization algorithm to estimate the unconfined compressive strength of stabilized cohesive soils using geopolymers [23]. Kong et al. studied the changes in mechanical, structural, and mineralogical properties of nano- $\mathrm{SiO}_{2}$-treated loess with different contents and curing periods, by evaluating the unconfined compressive strength of untreated and treated loess [24]. Fiber and cement can improve the strength of slurry. Fiber and cement-modified slurry can be used as road material. According to Chinese Test Methods of Materials Stabilized with Inorganic Binders for Highway Engineering (JTG E512009) and Technical Guidelines for Construction of Highway Roadbases (JTG/T F20-2015), 7-day unconfined compressive performance is an important mechanical index of road materials. Mechanical properties of fiber cementreinforced slurry vary with curing age. In this current study, unconfined compression tests were conducted for 7-daycured specimens with a cement content of 5\%,10\%, 15\%, $20 \%, 25 \%$, and $30 \%$, respectively. Moreover, the effects of fiber contents $(0.25 \%, 0.5 \%, 0.75 \%$, and $1 \%$, respectively) were also investigated for the specimens with a cement content of $20 \%$. Five variables, including peak strength, failure strain, initial elastic modulus, residual strength, and energy dissipation obtained through unconfined compression testing, were used to characterize the short-term strength properties of fiber/cement-modified slurry.

\section{Testing Materials}

The waste slurry was collected from the bored piles in a construction site in Shaoxing city of China. Figure 1 shows the slurry after preliminary dehydration treatment. In terms of chemical composition, the contents of $\mathrm{SiO}_{2}$ and $\mathrm{Al}_{2} \mathrm{O}_{3}$ in the slurry are $67 \%$ and $15 \%$, respectively. There are also small amounts of $\mathrm{CaO}, \mathrm{MgO}, \mathrm{Fe}_{2} \mathrm{O}_{3}$, and $\mathrm{K}_{2} \mathrm{O}$ in the slurry. The water content of the slurry was about $100 \%$. The cement used in testing was CEM I $32.5 \mathrm{R}$. As the water content in the slurry was high, the cement content (amount of cement over the dry weight of slurry) was set as $5 \%, 10 \%, 15 \%, 20 \%, 25 \%$, and $30 \%$, according to the study by Sukontasukkul and Jamsawang [14].

Polypropylene fiber (Figure 2) was used for testing, with basic mechanical properties as listed in Table 1. Different fibers have different effects on the strength of cement-soil, as the PP fibers have high tensile strength $(260 \mathrm{MPa})$, and they are not easy to agglomerate in cement-soil. Compared with glass fibers, the PP fibers can interact with cement-soil and improve its ductility. So, we chose PP fibers to reinforce

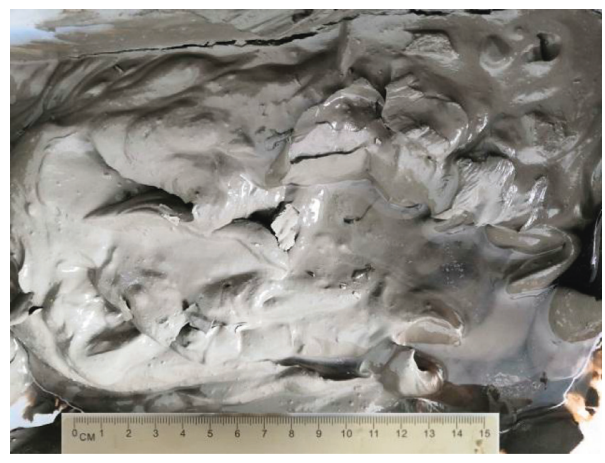

FIgURE 1: Slurry after preliminary dehydration treatment.

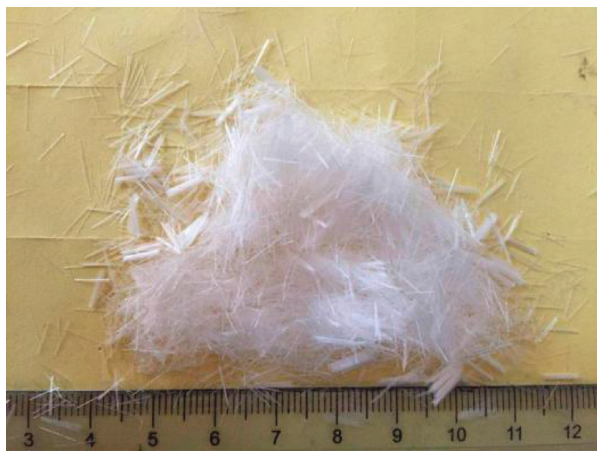

Figure 2: Polypropylene fiber.

cement-stabilized slurry. The influence of different fiber lengths on the strength of samples is different. Because the diameter of the sample is $39.1 \mathrm{~mm}$, if the fiber is too short, the fiber has little effect, and if the fiber is too long, it will affect the quality of sample preparation. The change of the fiber length is not considered in this study. According to [18], when the length of the fiber is $6 \mathrm{~mm}$, not only the effect of the fiber is obvious but also the quality of the sample can be guaranteed. So, in this study, $6 \mathrm{~mm}$ PP fibers were selected. For $20 \%$ cement content, the fiber contents (mixing amounts of the fiber relative to the dry weight of slurry) were $0 \%, 0.25 \%, 0.5 \%, 0.75 \%$, and $1 \%$, respectively, according to [14-18].

\section{Unconfined Compression Testing}

3.1. Specimen Preparation and Testing. The cement was weighed according to mix proportion and added to the slurry, and the mixture was then mixed homogeneously for $5 \mathrm{~min}$. Polypropylene fiber was then added to the mixture during stirring, and the mixture was stirred again for $3 \mathrm{~min}$. The mixture was then put into the PVC moulds and vibrated to get rid of the air bubbles. Then, the specimens were put in water at a temperature of $20^{\circ} \mathrm{C} \pm 2^{\circ} \mathrm{C}$ to be cured for 7 days. Figure 3 shows demolded specimens of unconfined compression test, with a height of $80 \mathrm{~mm}$ and a diameter of $39.1 \mathrm{~mm}$. Unconfined compression test was performed according to the "Standard for Soil Test Method" (GB/T 50123-1999), with a loading rate of $1 \mathrm{~mm} / \mathrm{min}$. 
TABLE 1: Mechanical properties of polypropylene fiber.

\begin{tabular}{lccccc}
\hline Fiber type & Tensile strength $(\mathrm{MPa})$ & Elastic modulus $(\mathrm{GPa})$ & Relative density & Length $(\mathrm{mm})$ & Diameter $(\mathrm{mm})$ \\
\hline Bundle filaments & 260 & 3.8 & 0.91 & 6 & 0.023
\end{tabular}

Bundle filaments means multifilament short fibers.

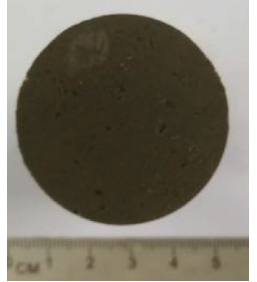

(a)

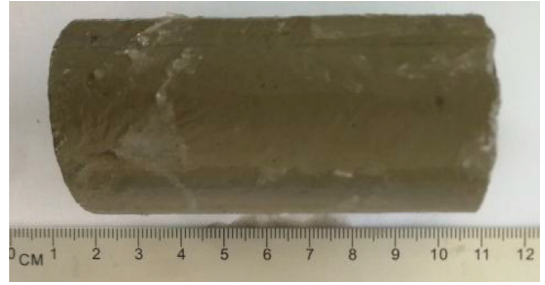

(b)

FIGURE 3: Fiber/cement-modified slurry specimens for unconfined compression test.

3.2. Testing Results. Figures 4 and 5 show the failure modes of modified slurry specimens obtained through unconfined compression test, for the cases of without and with fiber, respectively. It can be identified from Figures 4 and 5 that the failure surface of the modified slurry is around $45^{\circ}$ to the horizontal plane, showing the unconfined compression test.

Figures 6 and 7 show some typical stress-strain curves of the fiber/cement-modified slurry. It can be seen that they are strain-softening curves, meaning that with an increase in strain, the stress increases first and reaches its peak value, and then it gradually decreases with strain.

\section{Unconfined Compressive Strength}

4.1. Parameters of Unconfined Compressive Strength. Figure 8 shows a typical strain-softening curve during unconfined compression test, with the function expression of $\sigma=\sigma(\varepsilon)$.

Several important characteristic parameters could be extracted from the curve, including peak strength $q_{u}$, failure strain $\varepsilon_{u}$, initial elastic modulus $E_{0}$, and residual strength $q_{c}$. The function expressions of these parameters are stated in equations (1)-(4), respectively.

$$
\begin{aligned}
& q_{u}=\max \sigma(\varepsilon), \\
& q_{u}=\sigma\left(\varepsilon_{u}\right), \\
& E_{0}=\left.\frac{d \sigma(\varepsilon)}{d \varepsilon}\right|_{\varepsilon=0}, \\
& q_{c}=\lim _{\varepsilon \longrightarrow \infty} \sigma(\varepsilon) .
\end{aligned}
$$

The loading process of unconfined compression test can be treated as a process of energy concentration and release. According to the law of energy conservation, work done by axial force $F$ during testing can be used to characterize energy dissipation during the loading process, as shown in Figure 9.

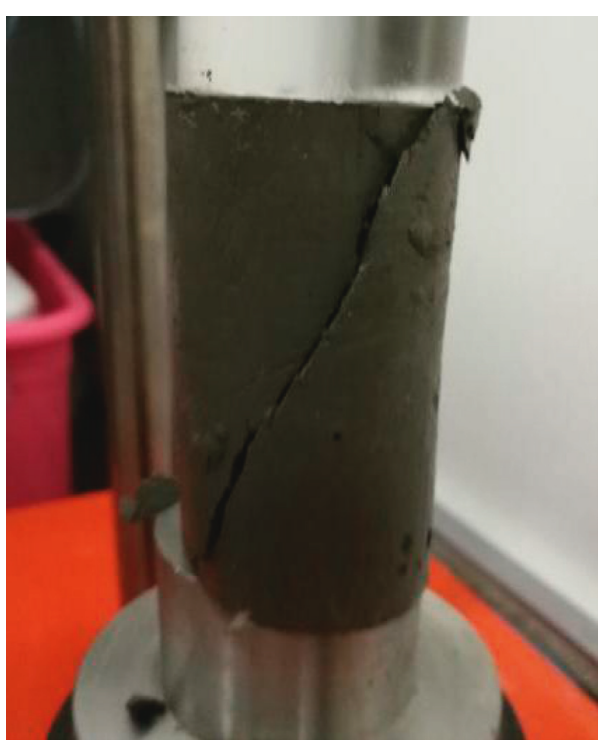

FIgURE 4: Failure mode of cement-admixed slurry specimen with a cement content of $20 \%$.

$$
W_{s}=\int_{0}^{s^{*}} F \mathrm{~d} s
$$

where $F=\sigma(\varepsilon) A ; s=\varepsilon H ; A$ and $H$ are sectional area and height of the specimen, respectively. In this study, $A$ was $1200 \mathrm{~mm}^{2}$ and $H$ was $80 \mathrm{~mm}$. Substituting $F$ and $s$ into equation (5) yielded

$$
W_{s}=A H \int_{0}^{\varepsilon^{*} H} \sigma(\varepsilon) \mathrm{d} \varepsilon
$$

According to "Standard for Soil Test Method" (GB/T 50123-1999), $\varepsilon^{*}=\varepsilon(u)+5 \%$.

4.2. Fitting the Stress-Strain Curves Based on BP Neural Network. Based on the analysis above, the key factor to characterizing the strength properties is to accurately establish the function relationship between stress and strain during unconfined compression test. Because of the 


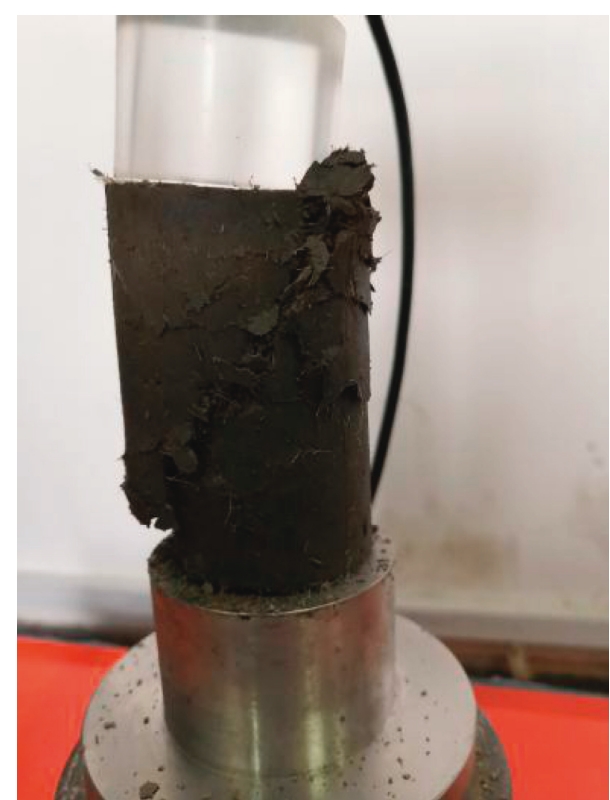

FIGURE 5: Failure mode of cement and fiber admixed slurry specimen with a cement content of $20 \%$ and a fiber content of $1 \%$.

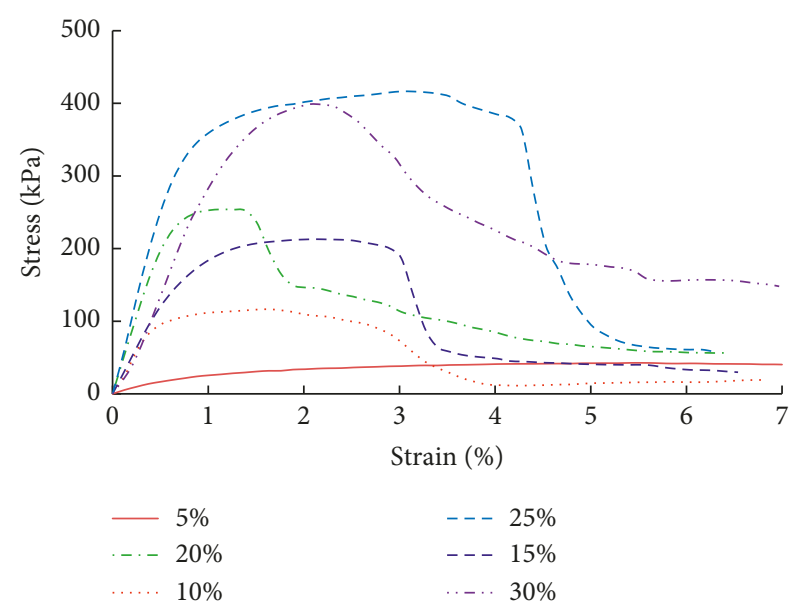

FIGURE 6: Stress-strain curve of cement-admixed slurry with different cement contents.

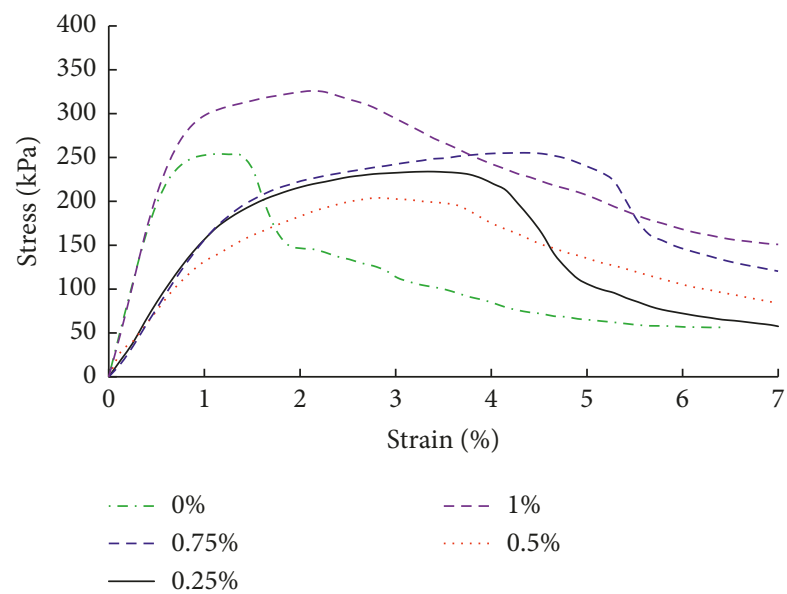

FIGURE 7: Stress-strain curve of cement and fiber admixed slurry with a cement content of $20 \%$ and different fiber contents.

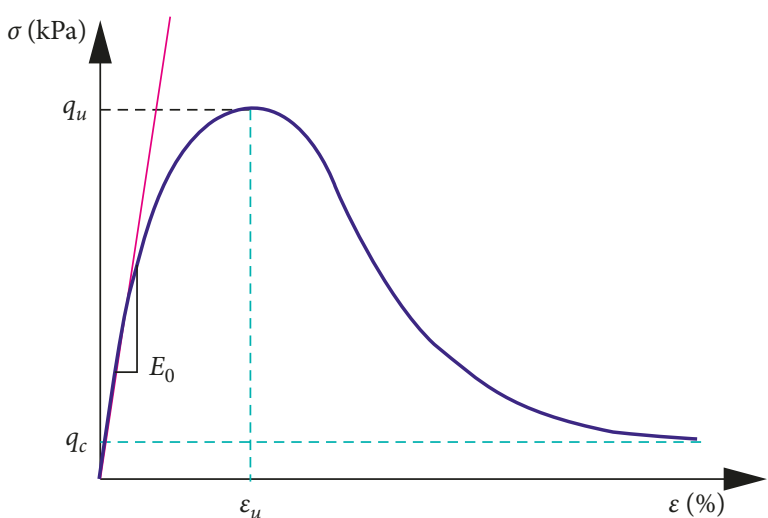

FIGURE 8: Typical stress-strain curve occurred during unconfined compression test.

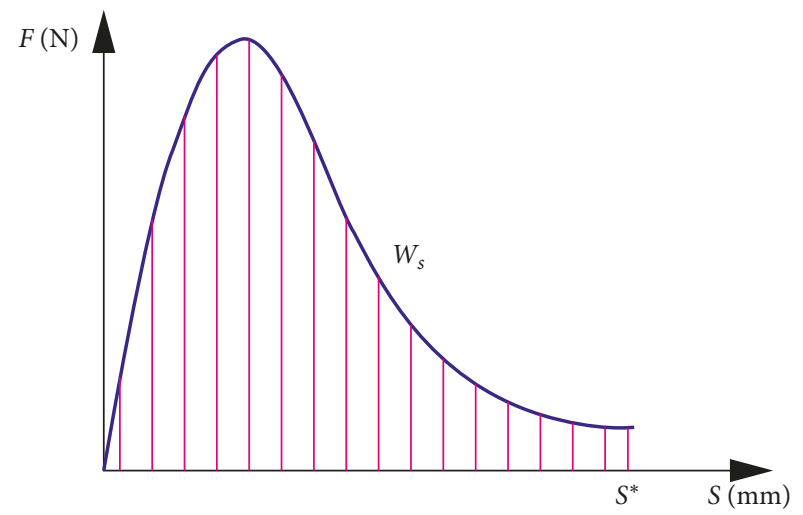

FIGURE 9: Energy dissipation during unconfined compression test.

heterogeneity in specimen preparation and discreteness as well as a systematic error during of testing, a data-fitting algorithm with an anti-interference feature was required. The BP neural network algorithm could achieve the precision of fitting by continually adjusting the weight value and offset value according to the back propagation of error, and with certain fault-tolerant characteristic. An appropriate neural network structure can simulate any nonlinear function relationship. Figure 10 shows the principle of information transfer in the BP neural network. In this study, the BP neural network algorithm was used to fit function relationship between stress and strain during unconfined compression test.

As the stress-strain curves obtained through every parallel test were not exactly coincident due to certain deviation as mentioned earlier, information of relationships between real stress and strain of each test was needed to effectively reduce experimental error. Thus, it can reasonably describe the strength properties of fiber/cement-modified slurry. As for the results of unconfined compression test of specimens with a certain mix proportion, strains of all specimens were combined as input variables of the BP neural network, and the corresponding stresses were combined as output variables. The mirroring and fault-tolerant capabilities of the BP neural network were fully utilized to fit and calculate the stress-strain curves. 


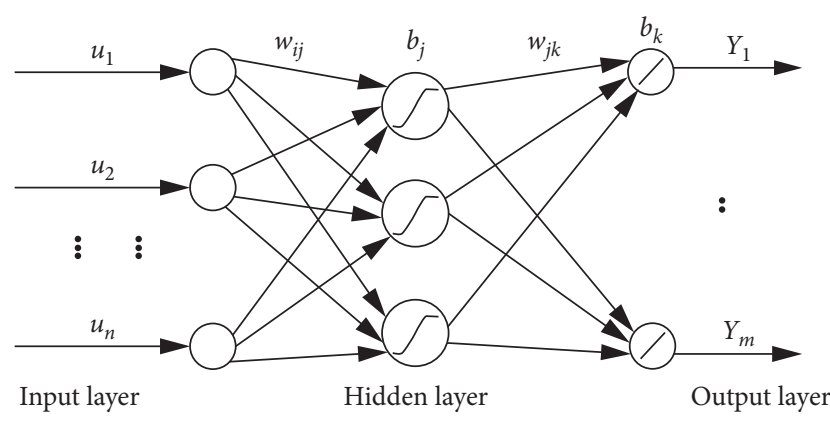

Figure 10: Calculation diagram of BP neural network [25].

In this study, the structure of the BP neural network was determined as one input-layer node, two hidden-layer nodes, and one output-layer node. Transfer functions of the hidden and output layers are stated in equations (7) and (8), respectively:

$$
\begin{aligned}
& f(v)=\frac{1}{e^{-v}+1}, \\
& f(v)=v .
\end{aligned}
$$

Normalization was necessary for the input and output variables to guarantee the precision of fitting $[25,26]$. After fitting, the functions of stress $(\sigma)$ and strain $(\varepsilon)$ were stated as follows:

$$
\sigma(\varepsilon)=\frac{a_{1}}{e^{-a_{2} \varepsilon-a_{3}}+1}+\frac{a_{4}}{e^{-a_{5} \varepsilon-a_{6}}+1}+a_{7}
$$

where $a_{1}=\left(\sigma_{\max } \omega_{21} / 2\right) ; a_{2}=\left(2 \omega_{11} / \varepsilon_{\max }\right) ; a_{3}=b_{11}-\omega_{11}$; $a_{4}=\left(\sigma_{\max } \omega_{22} / 2\right) ; \quad a_{5}=\left(2 \omega_{12} / \varepsilon_{\max }\right) ; \quad a_{6}=b_{12}-\omega_{12} ; \quad$ and $a_{7}=\left(\sigma_{\max } / 2\right)\left(b_{2}+1\right) . \omega_{11}, \omega_{12}, b_{11}, b_{12}, \omega_{21}, \omega_{22}$, and $b_{2}$ are the calculation parameters of the BP neural network. The specific meanings of these parameters are shown in Figure 10.

The relationship between stress and strain of fiber/cement-modified slurry with various fiber or cement contents could be obtained using equation (9), and the calculated data are summarized in Table 2. Table 2 lists the calculated results of fitting parameters in equation (9), while Figures 11 and 12 illustrate the fitting errors.

Figures 11 and 12 show that the BP neural network could reasonably fit the stress-strain curve of fiber/cement-modified slurry, with the maximum average error of $2.71 \mathrm{kPa}$ (see Table 2).

\subsection{Characterization of Strength Parameters}

4.3.1. Peak Strength $q_{u}$. The peak strength of fiber/cementmodified slurry with various fiber and cement contents could be obtained by substituting equation (9) and calculation data in Table 2 into equation (1), as shown in Figures 13 and 14 .

Figure 13 shows that the peak strength of cementmodified slurry gradually increased with the increase in the cement content. When the cement content increased from $5 \%$ to $25 \%$, the peak strength increased from $50 \mathrm{kPa}$ to $425 \mathrm{kPa}$. The peak strength almost increased linearly with the cement content, when cement content was within $15 \%$. However, when the cement content increased from $25 \%$ to $30 \%$, there was no obvious change in the peak strength.

Figure 14 shows that the peak strength fluctuated between 225 and $300 \mathrm{kPa}$ due to the influence of adding polypropylene fiber. This indicates that adding polypropylene fiber had an insignificant effect on the short-term peak strength of cement-modified slurry.

4.3.2. Failure Strain $\varepsilon_{u}$. The failure strain $\varepsilon_{u}$ of fiber/cementmodified slurry with various fiber and cement contents could also be obtained by substituting equation (9) and calculation data in Table 2 into equation (2), as shown in Figures 15 and 16.

Figure 15 shows that the failure strain of cementmodified slurry first decreased from $4.5 \%$ to $1.6 \%$ when cement content increased from 5\% to $10 \%$. After that, failure strain remained stable within cement content from $10 \%$ to $20 \%$. Then, it increased to $2.6 \%$ when cement content increased from $20 \%$ to $25 \%$, and then it tended to be stable with the increase in the cement content. The reasons could be interpreted as follows: when the cement content was $5 \%$, the cement-modified slurry was characterized as a plastic material, which could suffer a large plastic deformation; when the cement content was between $10 \%$ and $20 \%$, the cement-modified slurry could be characterized as brittle and its deformation performance would decrease with increasing force; when the cement content was between $25 \%$ and $30 \%$, the mechanical performance of cement-modified slurry may be dominated by the cementation bond and the failure strain of which tended to be stable.

Figure 16 shows that the failure strain of fiber/cementmodified slurry first increased for fiber content from 0 to $0.25 \%$. Then, it dropped slightly for fiber content from $0.25 \%$ to $0.5 \%$. When fiber content increased from $0.5 \%$ to $0.75 \%$, the failure strain would reach its maximum value of $3 \%$, and then it decreased to $1.6 \%$ when fiber content increased from $0.75 \%$ to $1 \%$. This indicates that a fiber content of $0.25 \%-$ $0.75 \%$ could increase the failure strain of fiber/cementmodified slurry, and $0.75 \%$ is the optimum fiber content in terms of increasing the ductility of the mixture, while the overuse of fiber (like fiber content of $1 \%$ ) had no obvious effect of the failure strain of the mixture.

4.3.3. Initial Elastic Modulus $E_{0}$. The initial elastic modulus $E_{0}$ of fiber/cement-modified slurry with various contents of fiber and cement could be obtained by substituting equation (9) and calculation data in Table 2 into equation (3), as shown in Figures 17 and 18.

Figure 17 shows that the initial elastic modulus E0 of cement-modified slurry first increased and then decreased with the increase of cement content. When the cement content was $5 \%-25 \%$, the initial elastic modulus $E_{0}$ of cement-modified slurry gradually increased from 3.6 to $52.6 \mathrm{MPa}$ (although there was a slight drop in cement content from $15 \%$ to $20 \%$ ); while the cement content was increased from $25 \%$ to $30 \%$, the initial elastic modulus E0 of 
TABLE 2: Calculated results of parameters in BP neural network.

\begin{tabular}{lcccccccc}
\hline Cement $(\mathrm{c})$ and fiber $(\mathrm{f})$ contents & $a_{1}$ & $a_{2}$ & $a_{3}$ & $a_{4}$ & $a_{5}$ & $a_{6}$ & $a_{7}$ & Average error (kPa) \\
\hline $5 \% \mathrm{c}$ & 27.3 & -1.28 & 9.72 & -2228896 & -0.94 & -10.98 & 12.38 & 0.16 \\
$10 \% \mathrm{c}$ & 173 & -1.05 & 3.07 & 2516991 & 1.11 & 9.6 & -2516987 & 1.37 \\
$15 \% \mathrm{c}$ & -135.6 & 2.12 & -6.68 & -332.9 & -3.53 & 0.32 & 194.6 & 0.61 \\
$20 \% \mathrm{c}$ & -188.8 & 0.77 & -2.19 & 421 & 2.38 & -0.45 & -138.9 & 2.71 \\
$25 \% \mathrm{c}$ & 366.7 & -1.58 & 7.55 & -14359490 & -1.11 & -10.32 & 95.3 & 0.32 \\
$30 \% \mathrm{c}$ & 344.4 & -1.17 & 5.9 & 578 & 2 & -1.61 & -443.6 & 0.19 \\
$20 \% \mathrm{c}+0.25 \% \mathrm{f}$ & 258.3 & -1.09 & 5 & -5265 & -0.79 & -2.77 & 38.87 & 0.17 \\
$20 \% \mathrm{c}+0.5 \% \mathrm{f}$ & 269.4 & -1.18 & 4.66 & 727.6 & 1.53 & 0.11 & -659 & 0.37 \\
$20 \% \mathrm{c}+0.75 \% \mathrm{f}$ & 195.4 & -1.08 & 5.66 & 581.3 & 1.26 & 0.035 & -511 & 2.04 \\
$20 \% \mathrm{c}+1 \% \mathrm{f}$ & 7227669 & 1.55 & 9.85 & 310 & -1.17 & 3.36 & -7227592 & 0.64 \\
\hline
\end{tabular}

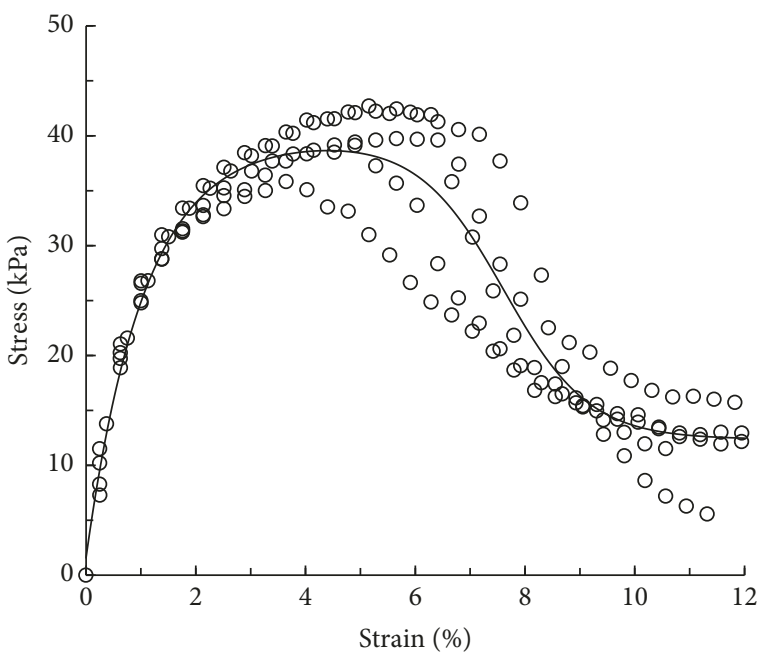

Experiment
- Calculation

FIGURE 11: Fitting result of stress-strain curve of cement-admixed slurry with cement content of $5 \%$.

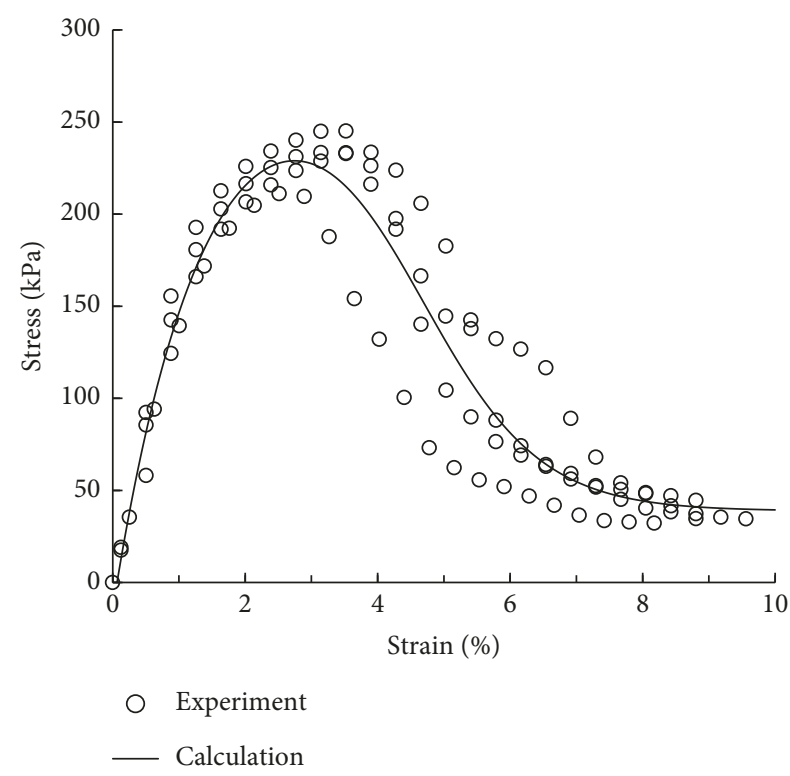

FIGURE 12: Fitting result of stress-strain curve of cement and fiber admixed slurry with a cement content of $20 \%$ and a fiber content of $0.25 \%$.

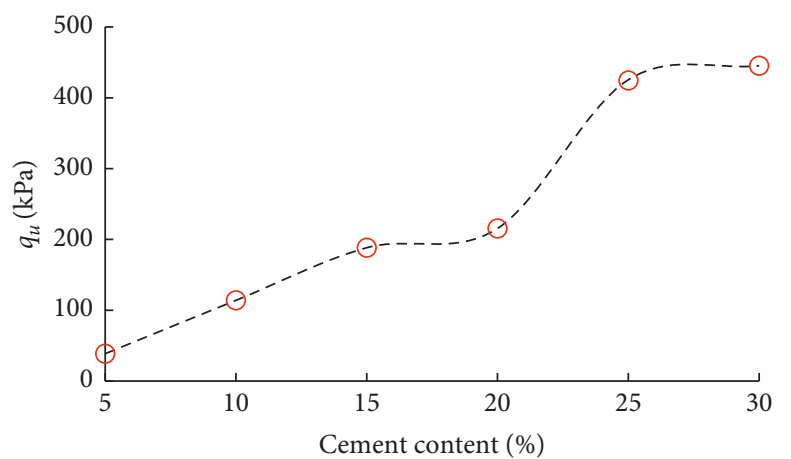

FIGURE 13: Peak strength $q_{u}$ of slurry with various cement contents.

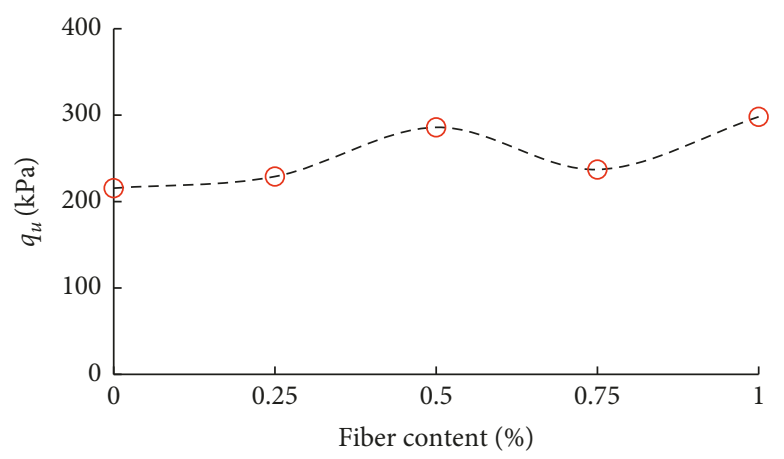

FIGURE 14: Peak strength $q_{u}$ of slurry with various fiber contents.

cement-modified slurry would decrease from 52.6 to 15.9 MPa.

Figure 18 shows that there was no obvious effect of fiber on the initial elastic modulus $E_{0}$ of fiber/cement-modified slurry for fiber content within $0.75 \%$. However, when the fiber content was increased from $0.75 \%$ to $1 \%$, the initial elastic modulus (E0) of fiber/cement-modified slurry increased from 12 to $57.7 \mathrm{MPa}$.

4.3.4. Residual Strength $q_{c}$. The residual strength $q_{c}$ of fiber/ cement-modified slurry with various fiber and cement contents could be obtained by substituting equation (9) and calculation data in Table 2 into equation (4), as shown in Figures 19 and 20. 


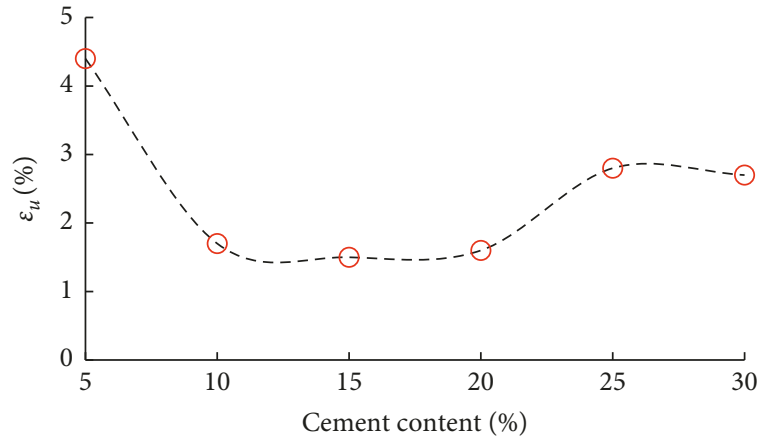

FIGURE 15: Failure strain $\varepsilon_{u}$ of slurry with various cement contents.

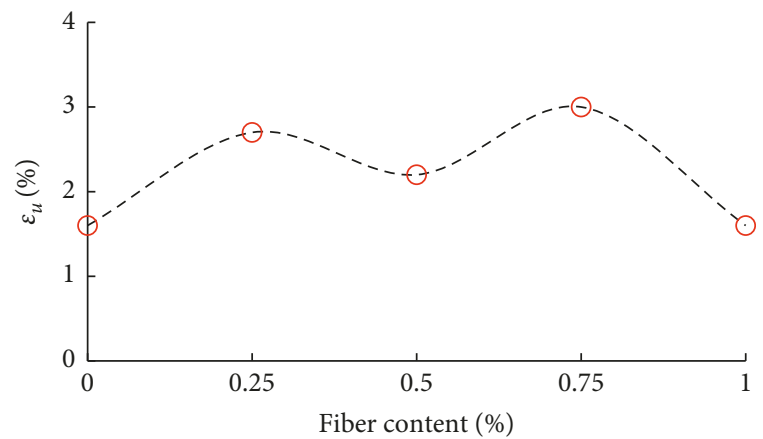

FIGURE 16: Failure strain $\varepsilon_{u}$ of slurry with various fiber contents.

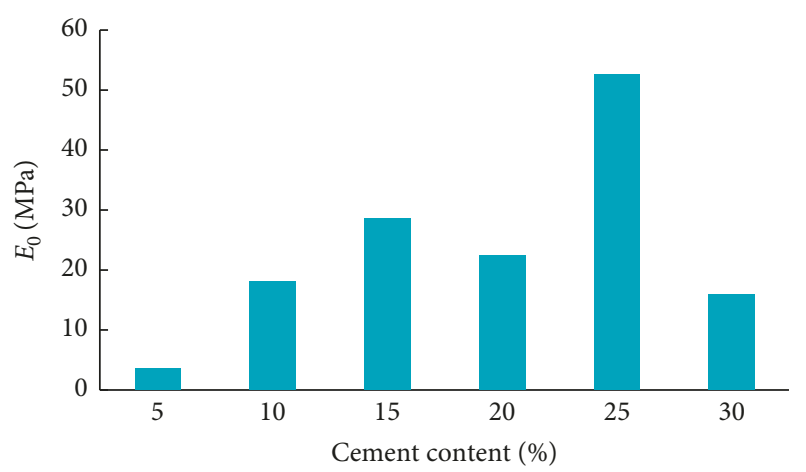

FIGURE 17: Initial elastic modulus $E_{0}$ of slurry with various cement contents.

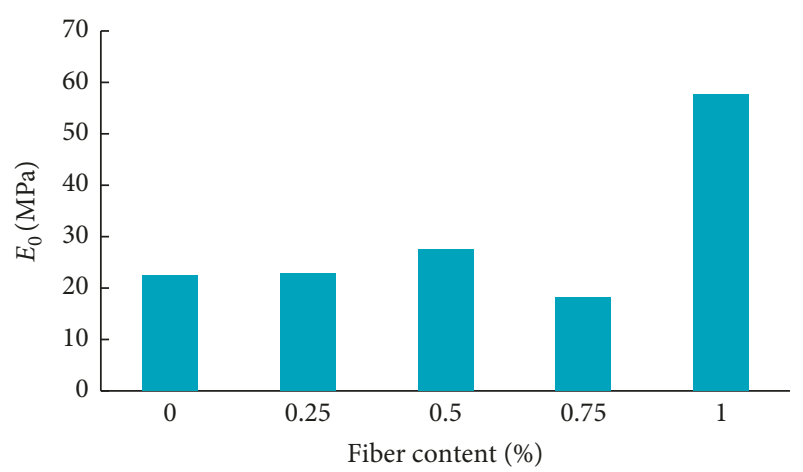

FIGURE 18: Initial elastic modulus $E_{0}$ of slurry with various fiber contents.

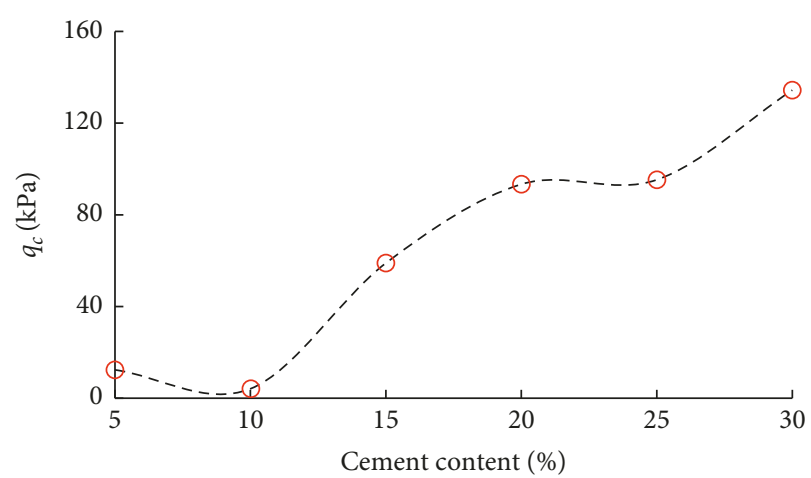

FIgURE 19: Residual strength $q_{c}$ of slurry with various cement contents.

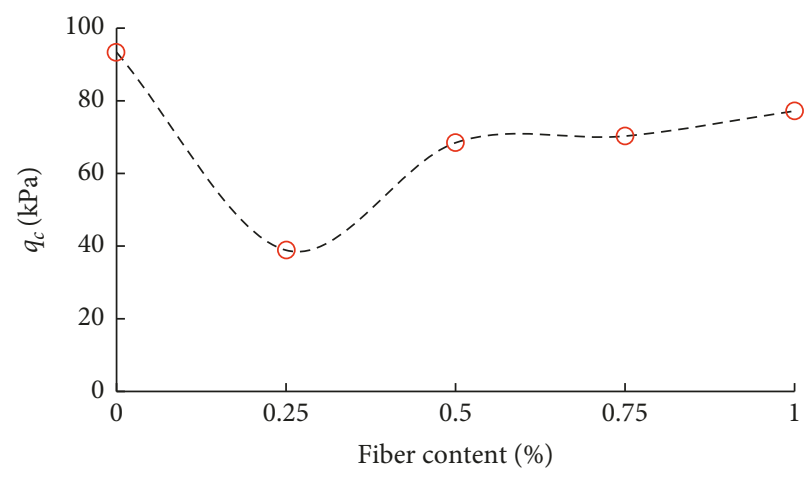

FIgURE 20: Residual strength $q_{c}$ of slurry with various fiber contents.

Figure 19 shows that the residual strength of cementmodified slurry gradually increased from 12.4 to $134.4 \mathrm{kPa}$ with the increase in the cement content from 5\% to $30 \%$, although there was a slight drop in cement content from $5 \%$ to $10 \%$.

Figure 20 shows that the residual strength $q_{c}$ of fiber/ cement-modified slurry first decreased from 93.3 to $38.9 \mathrm{kPa}$ for adding $0.25 \%$ fiber. Then, it increased from 38.9 to $77.1 \mathrm{kPa}$ for fiber content from $0.25 \%$ to $0.5 \%$, and it tended to be stable with the increasing fiber content from $0.5 \%$ to $1 \%$.

4.3.5. Energy Dissipation $W_{s}$. The energy dissipation $W_{s}$ of fiber/cement-modified slurry with various fiber and cement contents could be obtained by substituting equation (9) and calculation data in Table 2 into equation (6), as shown in Figures 21 and 22.

Figure 21 shows that the energy dissipation $W_{s}$ of cement-modified slurry gradually increased from 0.27 to $2.15 \mathrm{~J}$ with the increase in the cement content from 5\% to $30 \%$.

Figure 22 shows that there was no obvious variation of energy dissipation $W_{s}$, and it fluctuated between 0.96 and 1.21 J with fiber content. This indicates that adding polypropylene fiber had little influence in energy dissipation of short-term cured cement-modified slurry. This was because the interfacial strength among fiber, cement, and slurry could hardly play its role under this situation. 


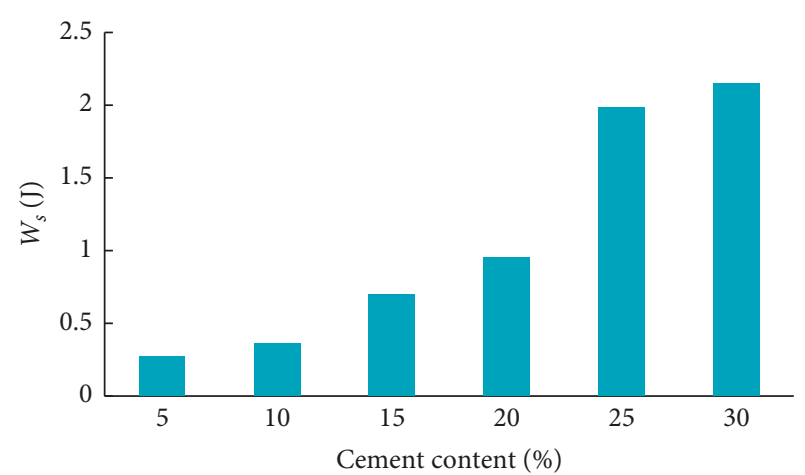

FIGURE 21: Energy dissipation $W_{s}$ of slurry with various cement contents.

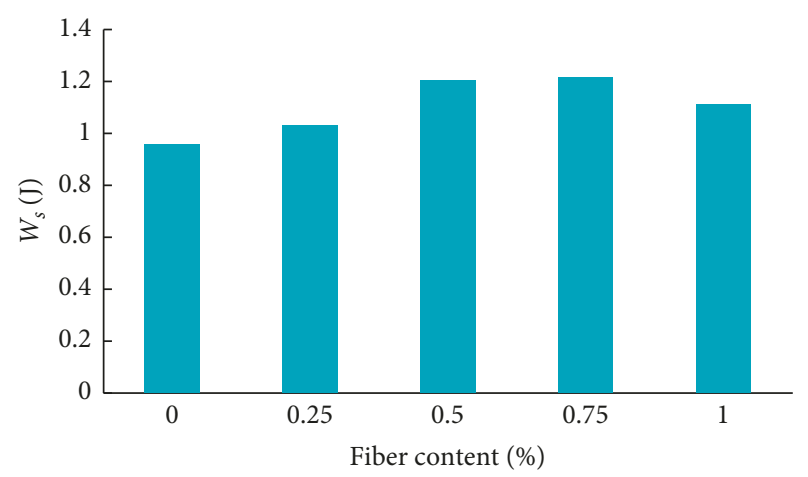

FIgURE 22: Energy dissipation $W_{s}$ of slurry with various fiber contents.

\section{Conclusion}

The conclusions of this study on unconfined compression test of $7 \mathrm{~d}$ fiber/cement-modified slurry were as follows:

(1) The BP neural network could accurately fit the stressstrain curve of the modified slurry during unconfined compression test.

(2) With the increase of cement content, the peak strength, residual strength, and energy dissipation of cementmodified slurry would increase. The initial elastic modulus increased first and then decreased, and the yield strain decreased first and then stabilized. Overall, cement content had a very significant impact on the strength properties of the modified slurry.

(3) With an increase of fiber content, the peak strength, residual strength, energy dissipation, initial elastic modulus, and failure strain illustrated unobvious variation. This implied that for short-term cured mixture (like 7 days in this study), the interfacial strength among fiber, cement, and slurry could hardly play its role due to insufficient hydration of cement.

\section{Data Availability}

The data used to support the findings of this study are included within the article.

\section{Conflicts of Interest}

The authors declare no conflicts of interest.

\section{Acknowledgments}

This research was funded by the National Natural Science Foundation of China (grant nos. 41772311 and 51568044), the Zhejiang Provincial Natural Science Foundation of China (grant no. LY17E080016), the Open Research Fund of Key Laboratory of Ministry of Education for Geomechanics and Embankment Engineering, Hohai University, the Open Research Fund of State Key Laboratory of Geomechanics and Geotechnical Engineering, the Institute of Rock and Soil Mechanics, Chinese Academy of Science (grant no. Z017013), the Scientific Research Projects of Zhejiang Department of Housing and Urban and Rural Construction of China (grant no. 2017K179), and the International Scientific and Technological Cooperation Projects of Shaoxing University (grant no. 2019LGGH1007).

\section{References}

[1] C. Coletti, G. Cultrone, L. Maritan, and C. Mazzoli, "How to face the new industrial challenge of compatible, sustainable brick production: study of various types of commercially available bricks," Applied Clay Science, vol. 124-125, pp. 219-226, 2016.

[2] M. Arsenovic, Z. Radojevic, and S. Stankovic, "Removal of toxic metals from industrial sludge by fixing in brick structure," Construction and Building Materials, vol. 37, pp. 7-14, 2012.

[3] K.-L. Lin, K.-W. Lo, M.-J. Hung et al., "Hydration characteristics of recycling reduction slag and waste sludge by cosintered treatment produced as eco-cement," Environmental Progress \& Sustainable Energy, vol. 36, no. 5, pp. 1466-1473, 2017.

[4] V. Mymrin, D. E. Pedroso, C. Pedroso et al., "Environmentally clean composites with hazardous aluminum anodizing sludge, concrete waste, and lime production waste," Journal of Cleaner Production, vol. 174, pp. 380-388, 2018.

[5] C. Martinez-Garcia, D. Eliche-Quesada, L. Perez-Villarejo, F. J. Iglesias-Godino, and F. A. Corpas-Iglesias, "Sludge valorization from wastewater treatment plant to its application on the ceramic industry," Journal of Environmental Engineering, vol. 95, pp. S343-S348, 2012.

[6] Y.-h. Chen, W.-l. Zhang, L.-y. Zhao, and Z.-h. Peng, "Field insitu stabilization of bored pile mud: engineering properties and application for pavement," Construction and Building Materials, vol. 165, pp. 541-547, 2018.

[7] Y. Zhang, Q. Guo, L. Li, P. Jiang, Y. Jiao, and Y. Cheng, "Reuse of boron waste as an additive in road base material," Materials, vol. 9, no. 6, p. 416, 2016.

[8] K. Yao, Q. Chen, J. Ho, H. Xiao, and F. H. Lee, "Strain-dependent shear stiffness of cement-treated marine clay," Journal of Materials in Civil Engineering, vol. 30, no. 10, Article ID 04018255, 2018.

[9] M. C. Rampini, G. Zani, M. Colombo, and M. di Prisco, "Mechanical behaviour of TRC composites: experimental and analytical approaches," Applied Sciences, vol. 9, no. 7, p. 1492, 2019.

[10] K. Yao, D. An, W. Wang, N. Li, C. Zhang, and A. Zhou, "Effect of nano-mgo on mechanical performance of cement stabilized 
silty clay," Marine Georesources \& Geotechnology, pp. 1-6, 2019.

[11] W. Wang, C. Zhang, N. Li, F. Tao, and K. Yao, "Characterisation of nano magnesia-cement-reinforced seashore soft soil by direct-shear test," Marine Georesources \& Geotechnology, vol. 37, no. 8, pp. 989-998, 2019.

[12] Y. Wang, P. Guo, X. Li, H. Lin, Y. Liu, and H. Yuan, "Behavior of fiber-reinforced and lime-stabilized clayey soil in triaxial tests," Applied Sciences, vol. 9, no. 5, p. 900, 2019.

[13] C. Tang, B. Shi, W. Gao, F. Chen, and Y. Cai, "Strength and mechanical behavior of short polypropylene fiber reinforced and cement stabilized clayey soil," Geotextiles and Geomembranes, vol. 25, no. 3, pp. 194-202, 2007.

[14] P. Sukontasukkul and P. Jamsawang, "Use of steel and polypropylene fibers to improve flexural performance of deep soil-cement column," Construction and Building Materials, vol. 29, no. 1, pp. 201-205, 2012.

[15] A. P. S. dos Santos, N. C. Consoli, K. S. Heineck, and M. R. Coop, "High-pressure isotropic compression tests on fiber-reinforced cemented sand," Journal of Geotechnical and Geoenvironmental Engineering, vol. 136, no. 6, pp. 885-890, 2010.

[16] L. Festugato, A. Fourie, and N. C. Consoli, "Cyclic shear response of fibre-reinforced cemented paste backfill," Géotechnique Letters, vol. 3, no. 1, pp. 5-12, 2013.

[17] N. C. Consoli, M. A. Vendruscolo, A. Fonini, and F. D. Rosa, "Fiber reinforcement effects on sand considering a wide cementation range," Geotextiles and Geomembranes, vol. 27, no. 3, pp. 196-203, 2009.

[18] L. Festugato, E. Menger, F. Benezra, E. A. Kipper, and N. C. Consoli, "Fibre-reinforced cemented soils compressive and tensile strength assessment as a function of filament length," Geotextiles and Geomembranes, vol. 45, no. 1, pp. 77-82, 2017.

[19] K. Yao, N. Li, D.-H. Chen, and W. Wang, "Generalized hyperbolic formula capturing curing period effect on strength and stiffness of cemented clay," Construction and Building Materials, vol. 199, pp. 63-71, 2019.

[20] W. Wang, N. Li, F. Zhang, A. Zhou, and S. Chi, "Experimental and mathematical investigations on unconfined compressive behaviour of costal soft soil under complicated freezing processes," Polish Maritime Research, vol. 23, no. 4, pp. 112-116, 2016.

[21] Y. Liu, Y. J. Jiang, H. Xiao, and F. H. Lee, "Determination of representative strength of deep cement-mixed clay from core strength data," Géotechnique, vol. 67, no. 4, pp. 350-364, 2017.

[22] N. C. Consoli, A. P. da Silva, H. P. Nierwinski, and J. Sosnoski, "Durability, strength and stiffness of compacted gold tailingscement mixes," Canadian Geotechnical Journal, vol. 55, no. 4, pp. 486-494, 2018.

[23] H. Javdanian and S. Lee, "Evaluating unconfined compressive strength of cohesive soils stabilized with geopolymer: a computational intelligence approach," Engineering with Computers, vol. 35, no. 1, pp. 191-199, 2018.

[24] R. Kong, F. Zhang, G. Wang, and J. Peng, "Stabilization of loess using nano-SiO ${ }_{2}$," Materials, vol. 11, no. 6, p. 1014, 2018.

[25] M. Li, H. Zhang, L. Liu, B. Chen, L. Guan, and Y. Wu, "A quantitative structure-property relationship model based on chaos-enhanced accelerated particle swarm optimization algorithm and back propagation artificial neural network," Applied Sciences, vol. 8, no. 7, p. 1121, 2018.

[26] P. Jiang, L. Qiu, N. Li, W. Wang, A. Zhou, and J. Xiao, "Shearing performance of lime reinforced iron tailing powder based on energy dissipation," Advances in Civil Engineering, vol. 2018, Article ID 4748526, 8 pages, 2018. 


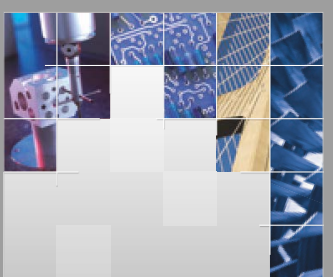

\section{Enfincering}
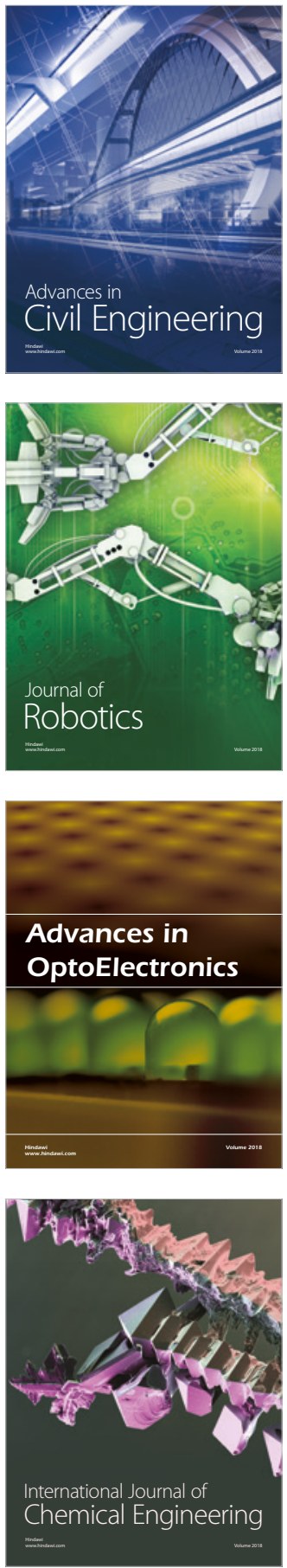

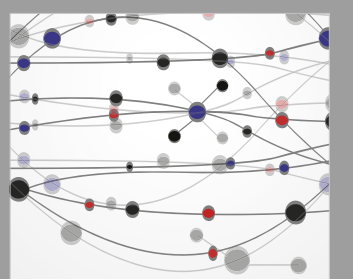

\section{Rotating \\ Machinery}

The Scientific World Journal

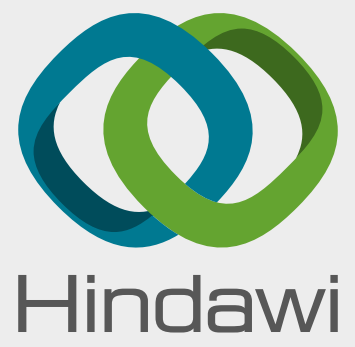

Submit your manuscripts at

www.hindawi.com
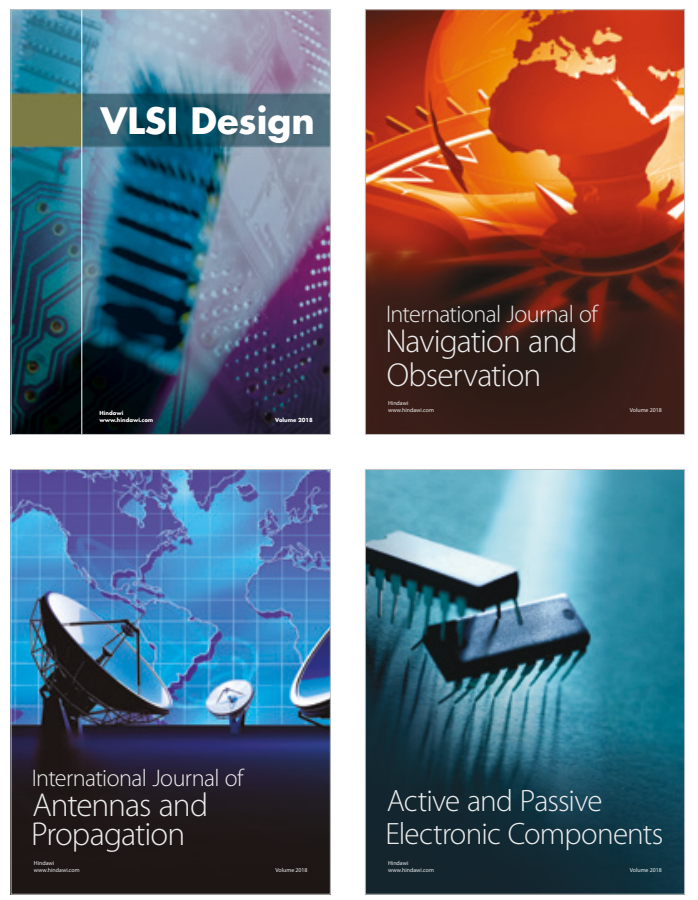
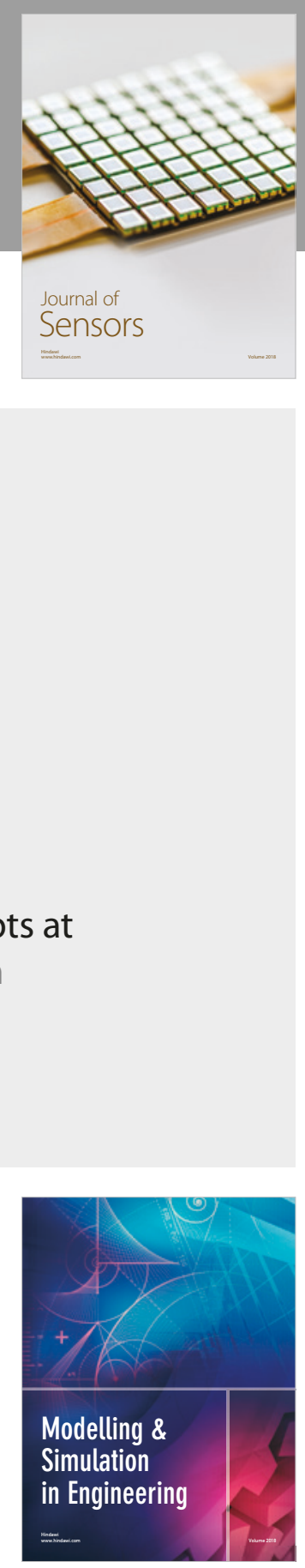

\section{Advances \\ Multimedia}
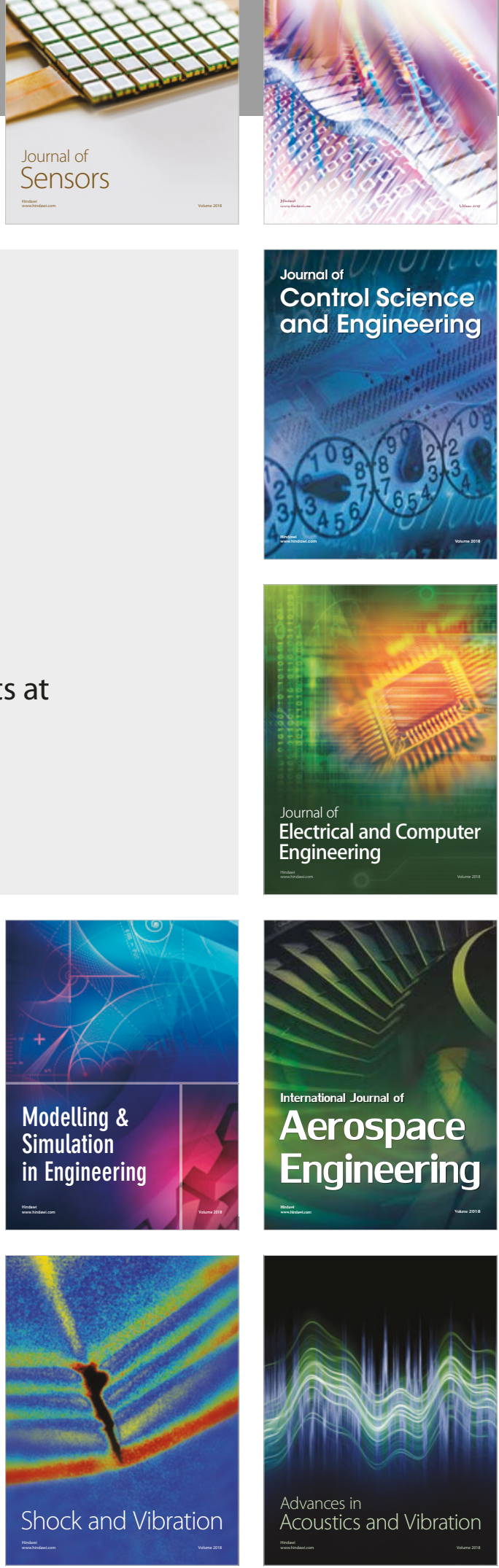